\title{
Use of Morphometry to Quantify Osteolysis after Total Hip Arthroplasty
}

\author{
Lindsay K. Smith MSc, MCSP, Fiona Cramp PhD, MCSP, \\ Shea Palmer PhD, MCSP, Nikki Coghill PhD, \\ Robert F. Spencer MD, FRCS
}

Received: 7 October 2009/ Accepted: 23 April 2010/Published online: 12 May 2010

(C) The Association of Bone and Joint Surgeons $\mathbb{R} 2010$

\begin{abstract}
Background Progressive osteolysis threatens the longevity of hip arthroplasties and radiographic review is recommended. Measurement of osteolytic lesions in a clinical setting has not been achieved easily in the past. Other radiologic investigations provide accurate information but cost and risk to the patient prohibit their use in routine review.

Questions/purposes We developed a simple, reliable tool to be used in hip arthroplasty review to quantify osteolytic changes seen on plain film radiographs.

Methods A morphometric grid was developed and tested on simulated and actual osteolytic lesions. Four health professionals measured lesions on each of two occasions. Intraclass correlation coefficients (ICC) for interobserver and intraobserver reliabilities were calculated and BlandAltman plots were constructed for graphic analysis.
\end{abstract}

Each author certifies that he or she has no commercial associations (eg, consultancies, stock ownership, equity interest, patent/licensing arrangements, etc) that might pose a conflict of interest in connection with the submitted article.

Each author certifies that his or her institution approved the human protocol for this investigation and that all investigations were conducted in conformity with ethical principles of research. This work was performed at Weston General Hospital and data analysis was conducted at the University of the West of England.

L. K. Smith ( $\varangle)$, R. F. Spencer

Department of Trauma and Orthopaedic Surgery,

Weston General Hospital, Grange Road, Uphill,

Weston-s-Mare BS23 4TQ, England

e-mail: smith@unforgettable.com

F. Cramp, S. Palmer, N. Coghill

School of Health and Social Care, Faculty of Health \& Life

Sciences, University of the West of England, Bristol, England
Results The ICCs for interobserver reliability on the simulated and actual osteolytic lesions were in the range 0.90 to 0.96 . The values for intraobserver (test-retest) reliability were 0.97 to 0.98 . The Bland-Altman plots confirmed agreement and in each case, proximity of the mean to zero indicated no significant bias.

Conclusions The data show a morphometric grid is reliable for measuring osteolytic changes after hip arthroplasty. Clinical Relevance This tool has potential to improve monitoring processes for hip arthroplasty and to be useful in future research studies. Additional work is needed to test for validity and clinical importance of the measurements obtained.

\section{Introduction}

There currently are more than 64,000 primary hip arthroplasties conducted annually in England and Wales, with as many as $10 \%$ subsequently requiring revision [26]. In the United States, the number of revision hip arthroplasties is expected to continue to increase in future decades [3]. Early causes of failure of the prosthetic joints include infection and recurrent dislocation, whereas late failure often is attributable to aseptic loosening and periprosthetic osteolysis [20, 43].

Osteolysis is a process of bone destruction in response to particulate wear debris $[9,16,18,24]$. It may develop silently $[1,22]$, but the associated deterioration of the host bone predisposes the patient to periprosthetic fracture or aseptic loosening and may compromise the success of a revision procedure [19, 43]. Consequently, periodic review of patients is recommended and should include radiographs to record progressive changes $[4,22,28]$. Failure to do so can have major consequences [27]. 
Assessment of substantial bone loss attributable to osteolysis often is made from radiographs using a categorical scale (eg, classification of Della Valle and Paprosky [7] or Saleh et al. [35]), which provides an indication of management at revision surgery. However, it has been suggested that assessment of earlier osteolytic changes should include such information as the shape, size, and location of lesions [9]. This requires more precise measurement to quantify progressive changes. The area of a lesion has been measured in numerous ways, including geometric formulae and computer software [15, 17, 31], but these techniques are not readily applied in routine clinical practice.

Use of plain radiographs in the assessment of pelvic osteolysis sometimes is debated, because accurate detection of a lesion in some locations is more difficult than with CT and MRI-51.7\% detected on radiographs compared with $74.7 \%$ by CT and $95.4 \%$ by MRI [41]. The use of CT with metal artifact suppression also has been shown to be more accurate for estimating the volume of osteolytic lesions [17, 22, 37]. However, the associated cost of CT or MRI and increased radiographic exposure for the patient (CT) preclude their use in routine screening. The addition of Judet oblique views to plain AP pelvic radiographs will improve sensitivity of detection from $41 \%$ to $73 \%$ and enable the observer to more precisely define the location of a lesion [5, 12, 40]. Consequently, it still is recommended that radiographic assessment be used in arthroplasty review [22, 39, 40].

Our purposes were (1) to develop the concept of a morphometric grid to provide a simple tool for measuring the area of osteolytic lesions and (2) to test the reliability of this tool to measure osteolytic lesions on radiographic films when used by a representative range of observers.

\section{Materials and Methods}

This observational study used the principle of cross intersect counting to develop a tool to measure the area of osteolytic lesions on radiographs. A morphometric grid is superimposed on the object of interest and the number of test points that fall within a defined area is counted.

Cross intersect counting has been used in biologic analysis for many years and it has been recommended that grid dimensions be chosen according to the object to be measured [10]. In radiographic assessment of hip arthroplasty, $2 \mathrm{~mm}$ is commonly used as a critical measurement of width of radiolucency [29]. Numerous authors consider linear radiolucencies greater than $2 \mathrm{~mm}$ a definite indication of loosening of the prosthesis [6, 8, 17, 34]. Therefore, a grid was developed and printed on transparency film with $2 \mathrm{~mm}$ between each point, which was a small cross at the intersection of grid lines. The uniformity of the spacing was checked by measuring fixed distances on each of three grids with electronic calipers. The mean of 15 measurements between six crosses $(10 \mathrm{~mm})$ was $9.98 \mathrm{~mm}$ (SD, $0.04 \mathrm{~mm}$ ). This was considered sufficient accuracy for the purposes of the study.

Interobserver and intraobserver (test-retest) reliability of the morphometric grid were tested using various observers, as recommended in the development of a new tool $[11,21$, $25,42]$. Four health professionals were selected to represent the range and levels of experience involved in arthroplasty review. They included a senior orthopaedic surgeon in hip arthroplasty (RFS, Observer 2), an orthopaedic registrar (MCP, Observer 4), a senior physiotherapist with more than 8 years' experience in reviewing hip arthroplasty but no experience in quantifying osteolysis (LP, Observer 3), and the primary author (LKS, Observer 1) who is a researcher and trained physiotherapist who currently does long-term surveillance of hip and knee arthroplasties.

The sample size was determined by taking into account the number of observers. It has been suggested a sample size of 20 to 50 observations is needed to obtain an intraclass correlation coefficient (ICC) with a standard error less than 0.05 [38]. Others recommend, at $80 \%$ power and $\alpha=0.05$, four raters would need to perform at least 30 observations each for a hypothesis test against a true reliability coefficient of 0.90 [11]. Consequently, a pragmatic decision was made to use 20 observations initially, as has been reported elsewhere [2, 33], and 35 observations at the second stage. For test-retest reliability, the observers reviewed the set of lesions twice with the recommended interval of 2 weeks [32, 38].

Initially, the reliability of the grid to measure area was tested using 20 simulated osteolytic lesions of varying size and shape (expansile and linear), represented as line drawings on white paper (Fig. 1). The images were reproduced in four booklets with a randomized order in each to reduce bias resulting from any learning effect. A simple description was provided to place the grid over the lesion and count the total number of crosses in the delineated area including any on the line. If no defined edge was provided, as with the simulation of some linear lesions, the individual observer decided the limit to mimic a clinical situation.

Additional booklets were produced with images in a new randomized order for repeat observations by two of the observers (RFS, LKS). There were no missing data and results from the measurements of the simulated lesions were analyzed before progressing to measurements on radiographs.

The second stage of testing was conducted on radiographs of joint arthroplasties with osteolytic lesions. There were 35 lesions around 27 joint arthroplasties, of which 11 

simulated expansile lesion (used for initial testing of the morphometric grid) with maximum dimension of $2.0 \times$ $0.9 \mathrm{~cm}$. Observer ratings of the number of crosses on the morphometric grid were $29,27,29$, and 32 .
Fig. 1 An example is shown of a

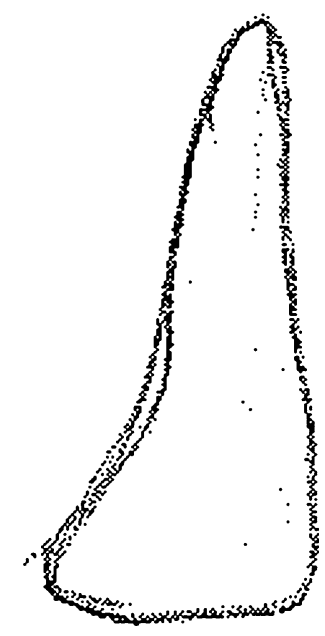

were cemented and 16 were hybrid (cemented femoral stem, uncemented acetabular cup). The location of the osteolysis was in the pelvis in eight $(23 \%)$ and the femur in $27(77 \%)$. Twenty-eight $(80 \%)$ of the lesions were expansile and seven (20\%) were linear; $20(57 \%)$ of them were associated with an uncemented component, and the remainder with cemented components. The joint arthroplasties had been in situ for 4 to 16 years (average, 8 years). The size of the lesions ranged from $0.04 \mathrm{~cm}^{2}$ to $2.2 \mathrm{~cm}^{2}$.

The method of testing the interobserver reliability of the morphometric grid was for each health professional to measure preidentified lesions. The lead author marked the general area but did not delineate the lesion precisely to allow individual interpretation of the size (Fig. 2). When more than one lesion existed on a radiograph, the lesion of interest was clearly identified. Not all lesions were included on any one radiograph as this study did not attempt to attribute clinical importance to the location or size of selected lesions, only to assess the reliability of the measurement tool.

Instructions were provided for placement of the grid, as before. An osteolytic lesion was defined as a clearly darkened area in which no trabeculae were visible compared with the adjacent bone or prosthesis. When composite shadow complicated the picture, observers were instructed to use the edge of the lesion as they estimated it to be regardless of shading. The observers were blinded to the identity of the patient and had no access to older images. Each observer recorded the number of crosses counted over each lesion and there were no missing data. The method of application of the morphometric grid is illustrated (Fig. 2).

Interobserver reliability was tested using an ICC, twoway random, absolute agreement method as the observers were representative of a larger population of potential users of the morphometric grid. Absolute agreement was used to

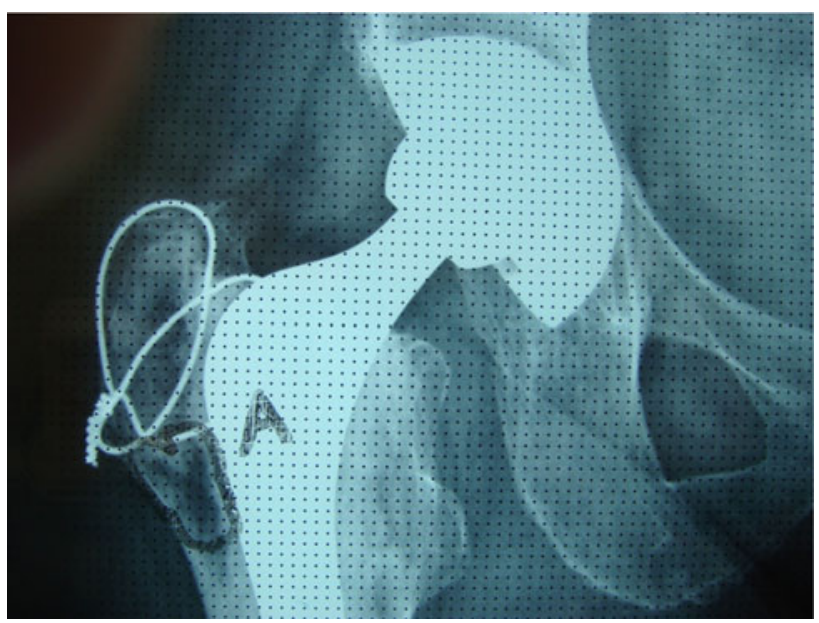

Fig. 2 The morphometric grid when superimposed on a radiograph for measurement of a femoral osteolytic lesion is shown. Observer ratings of the number of crosses for this lesion were 23, 21, 28 and 22.

provide a measure of consistency of the tool and the interchangeability of observers [36, 38]. Intraobserver reliability (test-retest) was tested with an ICC using a oneway random effects model; the people effects are random, but the same sample set is measured on each occasion.

The Bland-Altman method also was used, as it has been suggested the use of two methods provides a better estimation of agreement [25, 32, 33, 36]. The Bland-Altman method usually is applied to two sets of results at a time. A graphic plot is produced to show the differences between each pair of measurements in relation to the mean of each pair. Limits of agreement (mean difference \pm 2 standard deviations from the mean) are superimposed on this plot. It allows good visual representation of the reliability between two sets of observations [2]. The pairs of observers were chosen to reflect differences in profession and differences in experience in professional groups. We used SPSS $^{\circledR}$ Version 13.0 software (SPSS Inc, Chicago, IL) for the statistical analysis.

\section{Results}

The morphometric grid was first tested by the four observers for measurement of simulated lesions. The results of the intraclass correlation coefficients for interobserver and test-retest reliability are summarized in Table 1. The graphic plots of these results show the mean close to zero in each case (Figs. 3-5). They also show a wider dispersion of the points with increasing lesion size. This indicates a tendency for the difference between observers to be greater for the larger lesions. It can be seen that the test-retest plot for Observer 1 (Fig. 4) shows a greater tendency for this dispersion than the plot for 
Table 1. Results for interobserver and test-retest reliability on simulated lesions

\begin{tabular}{|c|c|c|c|c|c|c|c|}
\hline \multirow[t]{2}{*}{ Reliability } & \multicolumn{2}{|c|}{ Intraclass correlation coefficient } & \multicolumn{5}{|c|}{ Bland-Altman } \\
\hline & Coefficient & $\begin{array}{l}95 \% \text { confidence } \\
\text { interval }\end{array}$ & Range & $\begin{array}{l}\text { Mean } \\
\text { difference }\end{array}$ & $\begin{array}{l}95 \% \text { confidence interval } \\
\text { for mean difference }\end{array}$ & SD & $\begin{array}{l}95 \% \text { limits } \\
\text { of agreement }\end{array}$ \\
\hline Interobserver & 0.93 & $0.75-0.98$ & $3-55$ & 0.95 & $0-1.9$ & 2.04 & $-3.13-5.03$ \\
\hline Test-retest: Observer 1 & 0.97 & $0.93-0.99$ & $3-55$ & -1.05 & $-2.29-0.19$ & 2.65 & $-6.35-4.25$ \\
\hline Test-retest: Observer 2 & 0.98 & $0.95-0.99$ & $3-46$ & -0.45 & $-1.49-0.59$ & 2.21 & $-4.87-3.97$ \\
\hline
\end{tabular}

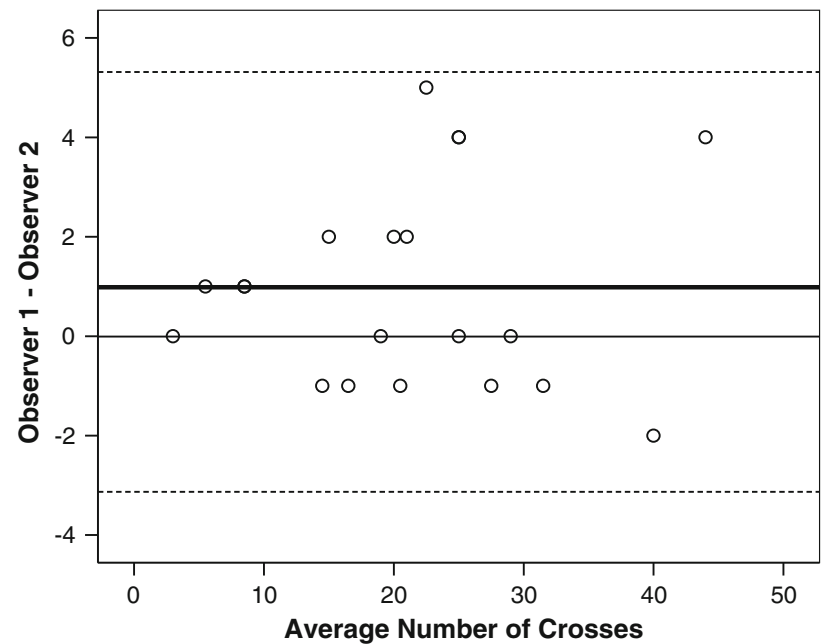

Fig. 3 A distribution plot from a Bland and Altman test for interobserver reliability of the morphometric grid when used with 20 simulated lesions is shown. Mean of differences is shown as a solid line; $95 \%$ limits of agreement are shown as dotted lines. (There are only 18 points shown on the graph, as there were two sets of identical results.)

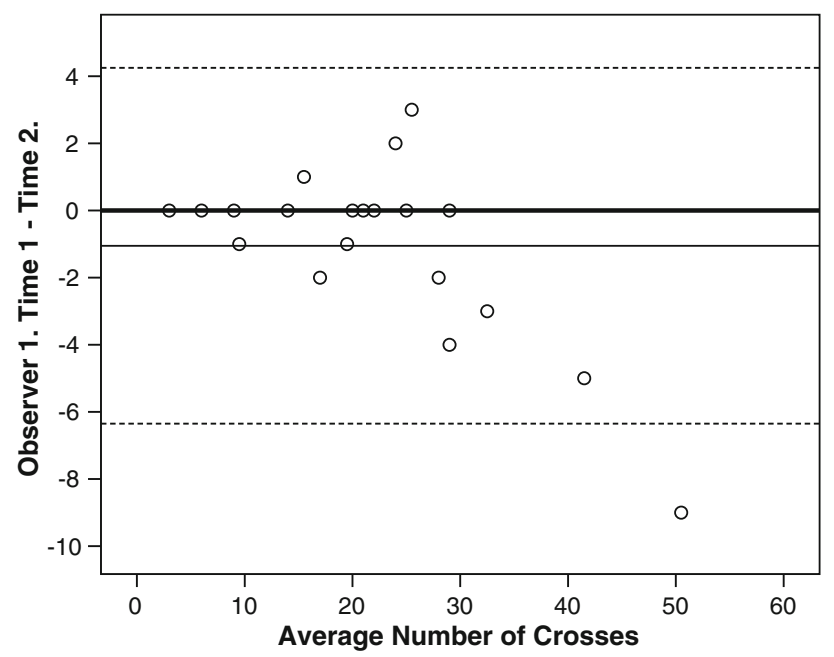

Fig. 4 A distribution plot from a Bland and Altman test for test-retest reliability of the morphometric grid when used with 20 simulated lesions (Observer 1) is shown. Mean of differences is shown as a solid line; $95 \%$ limits of agreement are shown as dotted lines.

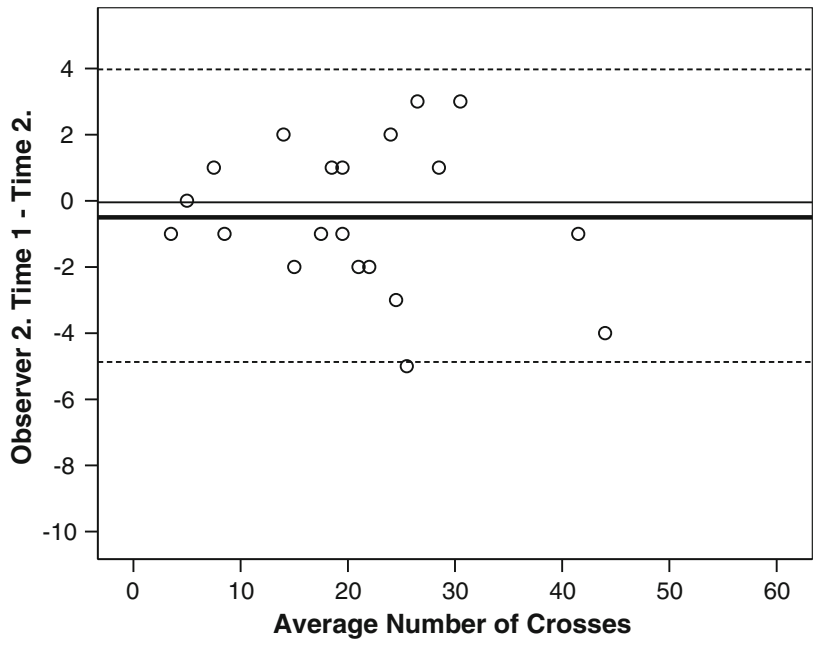

Fig. 5 A distribution plot from a Bland and Altman test for test-retest reliability of the morphometric grid when used with 20 simulated lesions (Observer 2) is shown. Mean of differences is shown as a solid line; $95 \%$ limits of agreement are shown as dotted lines.

Table 2. Intraclass correlation coefficient results for interobserver reliability on radiographs

\begin{tabular}{lll}
\hline $\begin{array}{l}\text { Interobserver } \\
\text { reliability }\end{array}$ & $\begin{array}{l}\text { Intraclass correlation } \\
\text { coefficient }\end{array}$ & $\begin{array}{l}95 \% \text { confidence } \\
\text { interval }\end{array}$ \\
\hline Time 1 & 0.96 & $0.93-0.98$ \\
Time 2 & 0.90 & $0.83-0.95$ \\
\hline
\end{tabular}

Observer 2 (Fig. 5), the latter being the more experienced observer of the two.

The reliability of the morphometric grid was subsequently tested on plain radiographs of hip replacements with osteolytic lesions in the surrounding bone. The four observers each recorded the size of 35 lesions and repeated the measurements 2 weeks later. The intraclass correlation coefficients between observers were 0.90 or greater on both occasions (Table 2). The Bland Altman method was used to assess reliability between four different pairs of observers (Observers $1 \& 2,3 \& 4,1 \& 3$, and $2 \& 4$; 
Table 3. Bland-Altman results for interobserver reliability on radiographs at Time 1

\begin{tabular}{llllrr}
\hline Observers & \multicolumn{2}{l}{ Bland-Altman } & & \\
\cline { 2 - 6 } & Range & $\begin{array}{l}\text { Mean } \\
\text { difference }\end{array}$ & $\begin{array}{l}\text { 95\% confidence interval } \\
\text { for mean difference }\end{array}$ & $\begin{array}{c}\text { SD } \\
\text { of agreement }\end{array}$ & $-7.83-7.21$ \\
\hline 1 and 2 & $2-64$ & -0.31 & $-1.60-0.98$ & 3.76 & 4.95 \\
3 and 4 & $1-71$ & -0.60 & $-2.30-1.10$ & 3.76 & $-10.50-9.30$ \\
1 and 3 (physiotherapists) & $2-63$ & 1.31 & $0.02-2.60$ & 5.40 & $-9.77-11.83$ \\
2 and 4 (surgeons) & $1-71$ & 1.03 & $-0.83-2.89$ & 5.83 \\
\hline
\end{tabular}

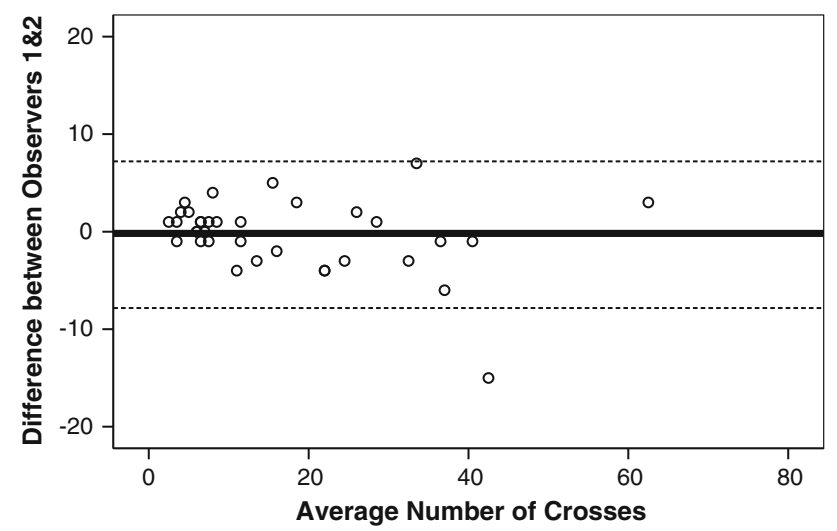

Fig. 6 A distribution plot from a Bland and Altman test of interobserver reliability of the morphometric grid when used to obtain measurements on 35 radiographs of hip arthroplasties (Observers 1 and 2) is shown. Mean of differences is shown as a solid line; $95 \%$ limits of agreement are shown as dotted lines.

Table 3) and an illustration of one of the resulting plots is provided (Fig. 6). As before, the mean was close to zero in each case but there was a greater difference between observers and between repeat observations for larger lesions.

\section{Discussion}

Progressive osteolysis is a threat to the longevity of a hip arthroplasty and regular followup of patients with serial radiographs ensures changes are monitored even in the absence of symptoms [4, 19, 39, 43]. The measurement of the area of osteolysis on radiographs has not been achieved easily $[9,12]$. Our aims were (1) to develop the concept of a morphometric grid to provide a simple tool for measuring the area of osteolytic lesions and (2) to test the reliability of this tool to measure osteolytic lesions seen on radiographic films when used by a representative range of observers.

We acknowledge limitations of our study. We used a two-dimensional tool to estimate the extent of a threedimensional lesion. In other studies of the relationship between area and volume, one study reported no direct relationship [5], but another reported a correlation, especially when a lesion was greater than $10 \mathrm{~mL}$ in volume [22]. We did not attempt to relate volume to area and additional testing would be required to investigate the association using the morphometric grid.

Additionally, we did not relate the size and location of lesions to clinical importance. Additional study would be required including relating the number of crosses on the grid to the actual area of the lesion being measured. Moreover, a study quantifying the crosses and location of lesions around hip replacements immediately before a revision would be useful in validating the grid for use in clinical diagnosis.

Our results suggest this simple tool can be used reliably to measure the area of osteolytic lesions in hip arthroplasty on radiographic film. A coefficient of reliability is a dimension less property of an instrument applicable when the tool is used in a specified way. The value of the coefficient is context based. Values of 0.75 to 0.90 have been described as "good to excellent reliability" [36], but elsewhere it is suggested the value should be 0.90 or more for clinical use [38]. Our ICCs were all 0.90 or greater for a range of observers which indicates high reliability and is comparable with other orthopaedic radiologic studies [13, 14]. This is an acceptable level of agreement for use of the measurement obtained as one part of the decision-making process for a patient when recommending invasive treatment such as revision surgery. A higher coefficient of reliability would be required if this tool was the sole source of information on which such a decision was based.

Although the Bland-Altman plots indicated a greater difference between observers and between repeat observations for larger lesions, this may be explained by the greater number of crosses to be counted. It could be improved by providing a grid with increased spacing $(>2 \mathrm{~mm}$ ) for larger lesions to optimize measurement by reducing the number of points to be included. It is of interest that the more experienced observer was more consistent in the measurement of size.

Although CT or MRI can provide three-dimensional assessment of the lesions, the cost, the risk to the patient, and the availability are barriers to their use in routine surveillance of patients with hip arthroplasties [22, 37, 40]. 
This simple, reliable tool requires no mathematical or software expertise and may be advantageous in a busy clinical situation when estimation of size is commonly made by visual analysis [31].

The interobserver reliability of this tool when used to measure osteolytic lesions identified on plain radiographs was 0.90 or greater (ICC), and on Bland-Altman plots, the mean was close to zero in each case, indicating no significant bias. The range of lesions measured represented commonly seen sizes, shapes (linear and expansile), and locations (pelvic and femoral). These results support the interchangeability of its use by any member of an orthopaedic team conducting routine surveillance. The purpose of surveillance is to facilitate timely intervention to improve the outcome for patients and potentially reduce the cost of surgery [23, 39, 43]. Additionally, reliable measurements obtained with the morphometric grid may provide evidence of the prevalence of osteolysis for specific acetabular components to assist a surgeon in his or her choice of prosthesis [39]. An essential component of this process is measurement of change over time with use of serial radiographs. Differences in magnification between radiographic films potentially could distort measurement of lesions made with the grid. However, the known diameter of the spherical femoral head provides a fixed measurement for calibration of films and the widely used digitized system for radiographs allows resizing of an image in the software provided. Transfer of the morphometric grid to a digital platform is being explored and it is recognized this must include consideration of measurement integrity when images are manipulated. The sensitivity of the grid to changes with time for use with progressive osteolysis must be investigated $[30,32]$, but should retrospective comparisons with plain radiographs be required, a formula (based on the size of the femoral head) can be used to compare the number of crosses observed (Appendix 1).

It is widely recognized there is a need for routine surveillance of patients who have had hip arthroplasties to monitor changes including development of asymptomatic osteolysis as a response to particulate wear debris. The use of radiographic review with AP and Judet oblique views allows assessment of pelvic osteolytic lesions, although estimates of volume usually require a CT scan or MR image. The routine assessment of area of osteolytic lesions on radiographic film often has been by visual analysis and the addition of a simple tool to quantify this assessment, developed from a morphometric grid, improves the reliability. This tool was reliable when used by a range of orthopaedic observers (medical and nonmedical health professionals) involved with hip arthroplasty review. It has potential to be incorporated in the assessment process to improve monitoring for patients who have had hip arthroplasties and may be a useful tool in future research studies.
Acknowledgments We thank M.C. Parry and L. Pattenden for their contribution to data collection.

\section{Appendix 1}

Formula to Adjust for Films of Differing Magnifications

If the morphometric grid is to be used on sequential plain radiographs of differing magnification, a simple formula can be used to adjust the number of crosses observed. For Film 1, the femoral head diameter $=\mathrm{F} 1$ and the size of the lesion on the grid $=\mathrm{N} 1$. For Film 2, the femoral head diameter $=\mathrm{F} 2$ and the size of the lesion on the grid $=\mathrm{N} 2$. The number of crosses for $\mathrm{N} 1$ then can be adjusted using the following formula: true number for $\mathrm{N} 1=(\mathrm{F} 2 / \mathrm{F} 1)^{2} \times$ N1. This true number for N1 can be compared with the number of crosses recorded for the other lesion (N2) to assess any change in size.

\section{References}

1. Barrack RL, Folgueras A, Munn B, Tvetden D, Sharkey P. Pelvic lysis and polyethylene wear at 5-8 years in an uncemented total hip. Clin Orthop Relat Res. 1997;335:211-217.

2. Bland MJ, Altman DG. Statistical methods for assessing agreement between two methods of clinical measurement. Lancet. 1986;1:307-310.

3. Bozic KJ, Kurtz SM, Lau E, Ong K, Vail TP, Berry DJ. The epidemiology of revision total hip arthroplasty in the United States. J Bone Joint Surg Am. 2009;91:128-133.

4. British Orthopaedic Association. Primary total hip replacement: a guide to good practice. 2006. Available at: http://boa.ac.uk. Accessed October 7, 2009.

5. Claus AM, Engh CA Jr, Sychterz CJ, Xenos JS, Orishimo KF, Engh CA Sr. Radiographic definition of pelvic osteolysis following total hip arthroplasty. $J$ Bone Joint Surg Am. 2003;85:1519-1526.

6. Dall DM, Learmonth ID, Solomon M. A scoring system to determine radiological loosening in cemented total hip arthroplasty. Int Orthop. 1992;16:339-343.

7. Della Valle CJ, Paprosky WG. The femur in revision total hip arthroplasty evaluation and classification. Clin Orthop Relat Res. 2004;420:55-62.

8. Duffy PJ, Masri BA, Garbuz DS, Duncan CP. Evaluation of patients with pain following total hip replacement. J Bone Joint Surg Am. 2005;87:2566-2575.

9. Dumbleton JH, Manley MT, Edidin AA. A literature review of the association between wear rate and osteolysis in total hip arthroplasty. J Arthroplasty. 2002;17:649-661.

10. Elias H, Hennig A, Schwartz DE. Stereology: applications to biomedical research. Physiol Rev. 1971;51:158-200.

11. Eliasziw M, Young SL, Woodbury MG, Fryday-Field K. Statistical methodology for the concurrent assessment of interrater and intrarater reliability: using goniometric measurements as an example. Phys Ther. 1994;74:777-788.

12. Geerdink $\mathrm{CH}$, Grimm B, Vencken W, Heyligers IC, Tonino AJ. Cross-linked compared with historical polyethylene in THA: an 8-year clinical study. Clin Orthop Relat Res. 2009;467:979-984. 
13. Ghelman B, Kepler CK, Lyman S, Della Valle AG. CT outperforms radiography for determination of acetabular cup version after THA. Clin Orthop Relat Res. 2009;467:2362-2370.

14. Gosvig KK, Jacobsen S, Palm H, Sonne-Holm S, Magnusson E. A new radiological index for assessing asphericity of the femoral head in cam impingement. J Bone Joint Surg Br. 2007;89:1309-1316.

15. Han CD, Choe WS, Yoo JH. Effect of polyethylene wear on osteolysis in cementless primary total hip arthroplasty: minimal 5-year follow-up study. J Arthroplasty. 1999;14:714-723.

16. Harris WH. Conquest of a worldwide human disease: particleinduced periprosthetic osteolysis. Clin Orthop Relat Res. 2004; 429:39-42.

17. Hernigou P, Zilber S, Filippini P, Poignard A. Ceramic-ceramic bearing decreases osteolysis: a 20 -year study versus ceramicpolyethylene on the contralateral hip. Clin Orthop Relat Res. 2009;467:2274-2280.

18. Holt G, Murnaghan C, Reilly J, Meek RM. The biology of aseptic osteolysis. Clin Orthop Relat Res. 2007;460:240-252.

19. Hozack WJ, Mesa JJ, Carey C, Rothman RH. Relationship between polyethylene wear, pelvic osteolysis, and clinical symptomatology in patients with cementless acetabular components: a framework for decision making. J Arthroplasty. 1996;11: 769-772.

20. Jacobs CA, Christensen CP, Greenwald AS, McKellop H. Clinical performance of highly cross-linked polyethylenes in total hip arthroplasty. J Bone Joint Surg Am. 2007;89:2779-2786.

21. Karanicolas PJ, Bhandari M, Kreder H, Moroni A, Richardson M, Walter SD, Norman GR, Guyatt GH; Collaboration for Outcome Assessment in Surgical Trials (COAST) Musculoskeletal Group. Evaluating agreement: conducting a reliability study. $J$ Bone Joint Surg Am. 2009;91(suppl 3):99-106.

22. Kitamura N, Pappedemos PC, Duffy PR III, Stepniewski AS, Hopper RH Jr, Engh CA Jr, Engh CA. The value of anteroposterior pelvic radiographs for evaluating pelvic osteolysis. Clin Orthop Relat Res. 2006;453:239-245.

23. Lavernia CJ. Cost-effectiveness of early surgical intervention in silent osteolysis. J Arthroplasty 1998;13:277-279.

24. Matthews JB, Besong AA, Green TR, Stone MH, Wroblewski BM, Fisher J, Ingham E. Evaluation of the response of primary human peripheral blood mononuclear phagocytes to challenge with in vitro generated clinically relevant UHMWPE particles of known size and dose. J Biomed Mater Res. 2000;52:296-307.

25. Morris RW. Assessing the reliability of clinical measurement. In: Pynsent PB, Fairbank JCT, Carr AJ, eds. Assessment Methodology in Orthopaedics. Oxford, UK: Butterworth-Heinemann; 1997:1-18.

26. National Joint Registry. 6th Annual report. 2009. National Joint Registry for England and Wales. Available at: http://www.njr centre.org.uk. Accessed October 7, 2009.

27. Needham J, Burns T, Gerlinger T. Catastrophic failure of ceramic-polyethylene bearing total hip arthroplasty. J Arthroplasty. 2008;23:627-630.
28. Nixon M, Taylor G, Sheldon P, Iqbal SJ, Harper W. Does bone quality predict loosening of cemented total hip replacements? J Bone Joint Surg Br. 2007;89:1303-1308.

29. Paterson D. The International Documentation and Evaluation System (IDES). Orthopedics. 1993;16:11-14.

30. Peat JK, Mellis C, Williams K, Xuan W. Health Science Research: A Handbook of Quantitative Methods. London, UK: Sage Publications; 2002.

31. Prevrhal S, Klifa CS, Shepherd JA, Ries MD, Genant HK. Computer-assisted technique to delineate osteolytic lesions around the femoral component in total hip arthroplasty. J Arthroplasty. 2008;23:833-838.

32. Pynsent PB, Fairbank JCT, Carr AJ. Outcome Measures in Orthopaedics and Orthopaedic Trauma. Ed 2. London, UK: Arnold; 2004.

33. Rankin G, Stokes M. Reliability of assessment tools in rehabilitation: an illustration of appropriate statistical analyses. Clin Rehabil. 1998;12:187-199.

34. Roder C, Eggli S, Aebi M, Busato A. The validity of clinical examination in the diagnosis of loosening of components in total hip arthroplasty. J Bone Joint Surg Br. 2003;85:37-44.

35. Saleh KJ, Holtzman J, Gafni A, Saleh L, Davis A, Resig S, Gross AE. Reliability and intraoperative validity of preoperative assessment of standardized plain radiographs in predicting bone loss at revision hip surgery. J Bone Joint Surg Am. 2001;83: 1040-1046.

36. Sim J, Wright C. Research in Health Care: Concepts, Designs and Methods. Cheltenham, UK: Nelson Thornes; 2000.

37. Stamenkov R, Howie D, Taylor J, Findlay D, McGee M, Kourlis G, Carbone A, Burwell M. Measurement of bone defects adjacent to acetabular components of hip replacement. Clin Orthop Relat Res. 2003;412:117-124.

38. Streiner DL, Norman GR. Health Measurement Scales: A Practical Guide to Their Development and Use. Ed 3. Oxford, UK: Oxford University Press; 2003.

39. Stulberg SD, Wixson RL, Adams AD, Hendrix RW, Bernfield JB. Monitoring pelvic osteolysis following total hip replacement surgery: an algorithm for surveillance. J Bone Joint Surg Am. 2002;84(suppl 2):116-122.

40. Thomas A, Epstein NJ, Stevens K, Goodman SB. Utility of Judet oblique $\mathrm{x}$-rays in preoperative assessment of acetabular periprosthetic osteolysis: a preliminary study. Am J Orthop (Belle Mead NJ). 2007;36:E107-E110.

41. Walde TA, Weiland DE, Leung SB, Kitamura N, Sychterz CJ, Engh CA Jr, Claus AM, Potter HG, Engh CA Sr. Comparison of CT, MRI, and radiographs in assessing pelvic osteolysis: a cadaveric study. Clin Orthop Relat Res. 2005;437:138-144.

42. Wright JG, Feinstein AR. Improving the reliability of orthopaedic measurements. J Bone Joint Surg Br. 1992;74:287-291.

43. Wroblewski BM, Siney PD, Fleming PA. Charnley low-friction arthroplasty: survival patterns to 38 years. J Bone Joint Surg Br. 2007;89:1015-1018. 